\title{
Online Activities to Mobilize Smart Cities
}

\author{
Mihoko Sakurai \\ University of Agder, Norway \\ Keio University, Japan \\ mihoko.sakurai@uia.no
}

\author{
Øystein Sæbø \\ University of Agder, Norway \\ oystein.sabo@uia.no
}

\begin{abstract}
A smart city is a dynamic living system that contains hard (unchanging) and soft (changing) parts that each involve the implementation of respective technologies. Prior research has focused on infrastructure, technology, and social components when discussing smart city structure. In this paper, we explore key elements within the soft aspects of smart city initiatives enabling the organization of a dynamic structure. To do so, we focus on human behavior, which we illustrate by analyzing online activities in two cases: one is related to a smart city while the other focuses on an online community. Based on the analysis, we identify key elements that reveal how people participate and become engaged in order to provide lessons to be taken into account within smart city initiatives. Within online activities, the key elements we note are related to knowledge generation, information sharing of common interests, and the creation of collective action.
\end{abstract}

\section{Introduction}

A city is composed of various elements that combine to create systems [1]. Elements such as people, infrastructure, roads, and shops are interdependent. For instance, traffic lights affect sales at the newsstand as people stop (and buy) when the light is red or pass by (without buying) when the light is green. Elements within systems contain both unchanging and changing parts. Unchanging parts refers mainly to parts that are stable once installed, such as buildings and infrastructure, while changing parts describes more dynamic aspects of the systems.

This dichotomy appears in the smart city concept, which contains hard and soft domains: hard domains include infrastructure such as buildings, transportation systems, and energy management systems while the soft domain category encompasses education, culture, and social inclusion [2]. People are naturally part of the soft category [1]. Information technology enables the performance of various tasks pertaining to city management, for instance, controlling energy consumption, creating effective transportation systems, connecting people within a community, and so on. All smart city initiatives around the world are promoted by technological innovation. There has been a strong demand for their implementation as urban development has been producing a lot of social problems, such as climate change, population growth, aging populations, pollution, unemployment, etc.

Prior research argues that both social and environmental sustainability are key elements within the smart city agenda [3]. In this sense, drawing insight from the aforementioned unchanging and changing element arguments, we could say that a city as a whole grows toward its sustainability goals; i.e., it is more than just the elements changing. Social aspects of sustainability reflect the quality of people's lives [4]. Urban performance largely depends on a city's endowment of human and social capital [5]. This perspective is often disregarded due to the focus of smart city research on technology use [2]. We found very few research which analyzes changing parts of a city. We should understand what key elements enable smart cities as a whole to change and grow as dynamic living systems. These dynamic living systems must take human behavior into consideration since the goal of such systems is to be sustainable and to tackle the various social problems described above. In this regard, this paper focuses on community building within a smart city project. From a technological aspect, we consider online activities as outcomes of human behavior and technology implementation in an urban city. Online activities are a driving force that enhances the participation and engagement of people, motivating them to actively take part in the shaping of their society and its political discourse [6]. 
Two questions are addressed in this paper. Based community building perspective, we see how the community development process was formed within a smart city project. A Japanese smart city case is used for this purpose. We analyze both offline and online activities in this case. Regarding online activities, we bring e-participation theories and use one case from Italy. In the second case, the question was framed as what kind of online activities and interaction actually are done by people to increase the level of participation and engagement. An intention is to combine insights from both smart city (community building) research and e-participation activities which provide us new perspective on how smart cities can be mobilized through the soft elements of a city.

The paper is structured as follows. First, we position our work within smart city research and conceptualize online activities based on eparticipation studies. Then, we propose a framework as a means of analyzing two cases. Based on the framework we explore the functioning of key elements of a smart city in each case. Finally, suggestions for public policies and future research topics derived from case analyses are presented, followed by a conclusion.

\section{Theoretical underpinnings}

In this section, we position our work within existing smart city research. For this purpose, we first summarize the smart city concepts discussed in prior research in order to understand the structure of a smart city. This structure, however, doesn't explain the dynamic process of change cities undergo as they grow. To supplement that gap, we review eparticipation theories in order to explore human behavior and technology implementation. We regard this as a first step toward understanding this dynamic process. We extract key elements pertaining to human activities from the e-participation field and propose our own framework for a smart city.

\subsection{Smart city concepts}

We notice that there is a growing body of literature discussing smart city concepts. Submitting a definition of a smart city is not within the scope of this paper; nevertheless, here we review the literature to understand how a smart city is structured.

A smart city is frequently discussed in terms of three dimensions, technological, institutional, and human [7], while reference is also made to physical infrastructure, social infrastructure, and technology [8]. The technological dimension features the integrated critical infrastructures of the city from which the smart city concept originally emerged. The institutional dimension deals with community issues that governance, policies, and regulations are used to cope with while the human dimension refers to the social capital and learning aspects of the city. What social infrastructure represents is similar to the human component, which includes education, health care, public spaces, intellectual capital, and social capital. They are all essential components that empower a smart city initiative.

Regarding the technology of a smart city, there are two core characteristics: (1) broad application of information technology to local communities in order to transform life and work within a region, and (2) embedded information and communication technologies provided to communities as a driving force of innovation, learning, and problem solving [3, 9]. Technology enhances the empowerment of people and gets them involved in conversations about how they live and how their lifestyles affect urban sustainability [3]. In other words, a smart city by nature requires people's participation and engagement in city management and governance [10].

When the community perspective is discussed in smart city research, the term smart community is often used. It describes a community in which government, business, and residents understand the potential of information technology and make a conscious decision to use that technology to transform life and work in their region in significant and positive ways [7]. Community-enabled cities are able to use fewer police officers and use gang intelligence in policing practices, thereby boosting cost-efficiency while improving results [11]. Moreover, technology enhances interconnectivity between local governments, schools, and neighborhood communities. In this sense, a smart community embeds networked/collective intelligence. It requires a great deal of work to make technologies effective in developing a sustainable community rather than choosing to build infrastructure [12].

To sum up, smart cities are being transformed into dynamic and evolving ecosystems rather than maintaining static infrastructures as before. This transformation is resulting in changes in the processes of service delivery between the government and citizens [13]. New forms of management and business models are required, compared to conventional city management. The design of a city's soft parts - its social, economic, and cultural aspects - is becoming as crucial as the development of hardware and infrastructure [14]. The integrated framework for smart city initiatives based on prior research is shown in Figure 1. It contains 
hard and soft elements while technology enables them to be "smart," creating a more dynamic process of change. This figure illustrates the structure of a smart city; however, it does not show how the dynamic process of change occurs within a smart city initiative. Hence, we now turn our attention to the process of how this dynamic change occurs. In particular, this paper focuses on the people and community perspectives, among other soft elements.

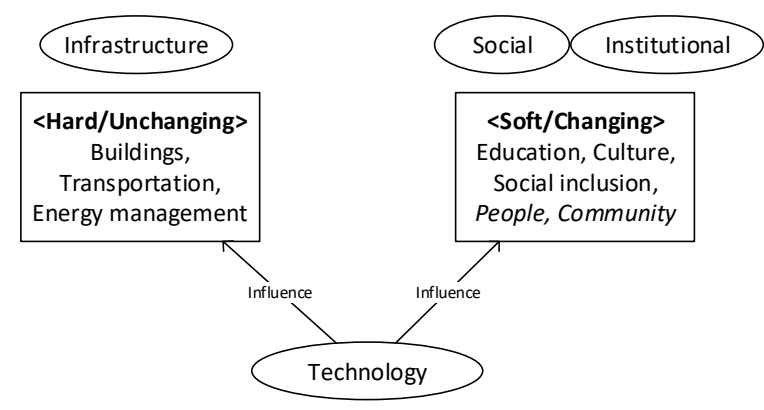

Figure 1. Smart city framework

As prior research recognizes social capital as an important component of a community, especially in engaging all stakeholders to participate in city management, our focus consequently centers on human behavior, which we believe guides us in understanding what actions are necessary for the formation and function of key elements of a city. The latest literature points out that collaboration has been one of the most discussed concerns in prior studies [8]. Collaboration between decision makers and other actors in smart city initiatives should be further explored. Reflecting our recognition of the central role of human behavior as presented in this section as well as the results from the latest studies, in the next section we look into e-participation theories to identify key activities that enhance people's participation using technologies.

\subsection{Online communities and e-participation}

The term e-participation encapsulates the processes and structures through which information and communication technology (ICT) supports relationships among citizens, governments, and public organizations $[6,15,16]$. Such implementations of ICT present new opportunities for communication, consultation, and dialogue between public organizations and citizens $[17,18]$.

A common strategy to involve groups of people to easily connect online and cooperate in a context of common and shared interests [19] is through the use of online communities (OCs). ICT makes resource sharing, information diffusion, and cooperation among groups of people who have sporadic physical contacts easy [20], giving rise to OCs that affect the actions and behaviors of individuals, teams, and organizations [21]. An OC is a persistent collection of people who communicate via the Internet [22], bypassing time and distance constraints [23]. The ubiquity of ICT has meant that the transaction costs of communication have dropped, making it easier for people to communicate and organize [24]. Unlike traditional communities, the preexisting social ties and material benefits of contributing are often weak or nonexistent in OCs [25], allowing broader, dynamic, organization-wide online sharing that is more flexible and fluid than in traditional communities [19].

When social media are used to support OCs, community members' actions are limited not only by the capabilities and hindrances of the underlying platform but also by the rules the $\mathrm{OC}$ has set to govern the collective collaboration [21]. At the same time, technology influences - and is influenced bythe surrounding organizational setting [26], while OCs are influenced by the social, cultural, and historical contextual conditions [27].

OCs may be regarded as fluid organizational forms oriented to innovation and other value-creating activities that require new forms of governance [28, 29]. In an OC, members cooperate if and when they agree that cooperation is advantageous for themselves and for the OC itself [30] in solving issues that could otherwise not be solved individually [31]. OCs are built for a variety of purposes, such as to manage relations with customers, to allow partners to cooperate in knowledge generation $[19,21]$, or to share information of public interest [32]. The communication flows through digital channels used by the OC to enable the collective action of members [33]. Structuring and managing the community to stimulate group actions and avoid adverse outcomes of independent actions is challenging [33]. Inside the community, there is a coexistence of an individual and a collective rationality, which poses challenges for the actual realization of a collective action of the community, where the communal objective prevails over individual goals.

Reflecting the points discussed in this section, the modified framework for a smart city is illustrated as follows (Figure 2). 


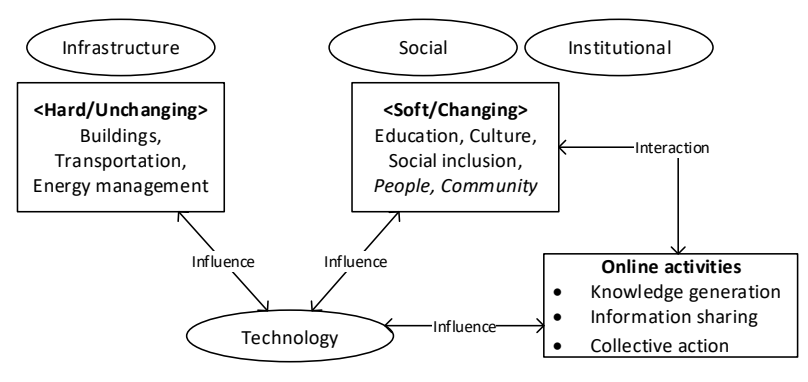

Figure 2. Smart city framework with actions

We find that there are key activities to enhance participation through technological means, namely knowledge generation, information sharing of common interest, and collective action. These activities support the dynamism of the soft elements of a smart city through interactions among people and their behaviors.

\section{Case descriptions}

In this section, we elaborate two case descriptions. The first case is about a smart city developed Panasonic, a Japanese manufacturing company. This represents the latest initiative in Japan regarding smart cities; it is still under development. One of the authors conducted a face-to-face interview with the management team leader and a team member of this smart city project in 2015. The team leader is responsible for the development of the project. Questions were exploratory, inquiring into how they designed the smart city and how they tried to involve people living in that city. The published information such as Panasonic's press release and project marketing documents were used as the secondary data. The second case has been investigated for several years, starting back in 2012. That case is (to our knowledge) the largest European initiative involving citizens directly in the political decisionmaking process. Around 20 face-to-face interviews (representatives, members of the community and citizens, identified by a snowball- approach) were conducted in several rounds, postings from the online community were investigated, while social media content was gathered and analyzed to further expand our understanding of the initiative. The intention of introducing this online community case, which is not directly connected to a smart city, is that we were able to apply analytical results to the study of smart cities with regard to understanding human behavior in terms of participation and engagement.

\subsection{Panasonic's sustainable smart town initiative (Japan)}

In spring of 2014, Panasonic, the leading Japanese electronics company, opened a smart town in Fujisawa City, $50 \mathrm{~km}$ from central Tokyo. The initiative had been taken by Panasonic in intensive collaboration with the government of the local municipality, Fujisawa City. The smart city covers an area of $0.2 \mathrm{~km}^{2}$ in Fujisawa City (note that the whole city covers $70 \mathrm{~km}^{2}$ ) and was named Fujisawa Smart Sustainable Town (FSST). Construction work on FSST is still ongoing but is expected to be completed in 2018. FSST will comprise 400 detached homes and 400 apartments as its residential component, a committee center (an assembly hall), commercial facilities, a wellness center, and a community solar power generation system by the time of completion. At the time of opening, FSST had 200 detached homes available to be sold. Three thousand residents will be living there by 2018. Panasonic created the city's guiding concept and motto, "Bringing energy to life," aiming to produce a better lifestyle and living environment aided by technology and products developed by Panasonic (note that the broad definition of energy used here is this: energy whereby people can live in peace and have secure, healthy lifestyles, gaining vitality through interaction).

To achieve the guiding concept, they developed five services in different fields: energy, security, mobility, wellness, and community. In the energy field, they created four targets as follows: $\mathrm{CO} 2$ emission rates were reduced by $70 \%$ (compared to the 1990s), water usage was reduced by 30\% (in comparison to 2006), there was an increase in renewable energy use up to $30 \%$, and three days' worth of emergency kits were secured. The houses would be equipped with solar power systems and rechargeable lithium-ion batteries as part of a system where energy is created and stored, putting into practice a self-sufficient system of energy creation and storage. Rather than transferring energy from power plants, which often results in a loss of energy from dissipated heat, this system will reduce energy loss, leading to more efficient use of energy.

The smart home energy management systems (HEMS) allow for inspection of the residents' energy use. After moving into the houses, residents would register their lifestyle and family structure to create individual records utilizing the energy data collected from HEMS. Water conservation measures for toilets, baths, and dishwashing machines have been introduced to reduce water usage by $30 \%$.

In the security field, 50 security cameras and LED street lamps have been installed, focusing on the 
city's entryway, public buildings (the wellness and committee centers), parks, and main roadways. Installed in each house are home security features such as intrusion detectors, fire detectors, and emergency alarms. Residents can access images taken by security cameras installed in parks using a tablet computer at home, ensuring the security and safety of their children playing there.

Regarding mobility, FSST provides a service whereby residents can share electronic cars and bicycles. As of July 2015, one electronic car had been placed next to the committee center in the city center, and two electronic cars had been placed in a garden space near the residences that used to be a parking lot.

Two towers will be built as a part of the "wellness square," which will include a special nursing home for the elderly and retirement housing with support services. The buildings will also contain a nursery school, a tutoring center, a clinic mall with a pharmacy, and space built for resident interaction. The Fujisawa City government requested the development of nursing homes for the elderly and nursery schools. To build this wellness square, people from different age groups gathered to plan its design and create a space that would encourage easy interaction among people. In the future, there is a plan to establish an integrated community care system that utilizes ICT, where residents' health information and various services, such as medical and nursing care, can be shared with the pharmacy. Not only is medical and nursery care provided but learning programs for children and services for lifelong learning will be available as well, creating a broad space for people outside of the city to interact with residents.

Usually, cities are based on their technological infrastructure, and concepts of sustainability are introduced during city development and residential development projects. Even cities known as smart cities around the world, such as Amsterdam, are still led by their technological infrastructure [34]. To avoid being too technologically oriented, FSST first designed initial residents' behaviors in line with the proposed "new lifestyle" covered by the five service fields in the town. From this perspective, communitybuilding is one of the most important responsibilities of the FSST management team. No community organization had existed in the area before, so a community needed to be developed from scratch. Thus, as part of the resident's association, the FSST committee was established; it includes residents and business operators within FSST. ICT was utilized to help form this community. Doing so connected key players inside the city and created the "town portal" (through the electronic notice board), which provides information such as how to gain access to services in the city (Figure 3).

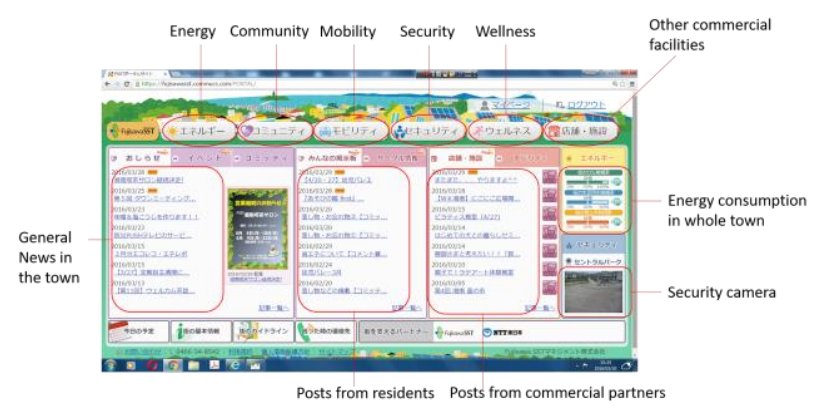

Figure 3. FSST town portal

\subsection{Online communities for political communication (Italy)}

The Italian Five Star Movement's (Movimento Cinque Stelle, M5S) use of ICT to encourage direct citizen participation in politics represents an exceptional example from which to glean information on e-participation. First, the M5S is new to Italy's political landscape and has in only a few years become influential at both the local and national levels, being the second-most-voted-for party in the country's 2013 parliamentary elections; indeed, the M5S has probably achieved more influence in less time than most (if not all) other e-participation political initiatives. Second, unlike many eparticipation political initiatives - which are overwhelmingly founded on existing political systems and focused on the interests of traditional stakeholders - the M5S was created by people who were not part of the established political elite. Third, the organization has, since its inception, coordinated all its activities using ICT tools, and this has allowed each of its supporters to participate in political debates and decision making.

The M5S is a political organization founded in 2009 by prominent former comedian Beppe Grillo and entrepreneur Gianroberto Casaleggio. Grillo was quite popular in Italy in the 1980s for his TV shows, which were characterized by strong and staunchly critical stances against the country's business, financial, and political establishment. Banned from TV in 1986 for his politically incorrect rhetoric, Grillo continued to perform in theaters and other venues across Italy. In 2005, he started a blog with the support of Casaleggio Associati Ltd., a company founded by Gianroberto Casaleggio. Grillo's popularity and reputation continued to grow as a result of his blog posts, and in 2009, he was ranked 
the world's seventh-most influential Web personality by Forbes Magazine. Over the years, Grillo's fans across Italy began organizing groups that were active in local politics. Using Grillo's blog as its main meeting place, a group called Amici di Beppe Grillo (Friends of Beppe Grillo) formed in 2005 to coordinate these local groups' activities. The smaller groups started using the social-networking platform Meetup.com, as per one of Grillo's suggestions, and the word Meetup soon became synonymous with local groups. These groups, moreover, organized nation- and region-wide events at which members met face-to-face and at which Grillo himself was often in attendance.

In 2008, several of these groups began creating candidate lists naming citizens unaffiliated with specific political parties. Furthermore, as stated above, the M5S was officially founded in 2009 to expand and build upon the Friends of Beppe Grillo and to provide a common political agenda for all the listed candidates. Grillo trademarked Movimento 5 Stelle, reserving all rights to the organization's brand to himself, and since, he has granted its usage to groups that adhere to a specific set of rules available online.

Since 2009, the number of active M5S groups on Meetup.com has grown from an initial 40 to 1,482 across 1,191 cities in 21 countries [6]. In Italy, the M5S has rapidly become a national political party and was the second-most voted-for party both in the 2013 national elections and 2014 EU elections. The M5S sharply distinguishes itself from Italy's traditional political parties by claiming to be more open, transparent, and representative. Notably, too, the M5S does not define itself as a party but as a platform for consultation and confrontation that originated on Grillo's blog. To distinguish itself even more thoroughly from traditional political parties, the M5S refers to itself as a "non-association."

The M5S introduced a set of ICT tools to help followers share information, discuss, make decisions, and set agendas. Elected representatives are expected to assert M5S subscribers' collective will as it is developed and expressed online. At the same time, representatives are required to inform citizens via ICT channels about ongoing activities within the political institution to which they have been elected. Some of the ICT tools are accessible to all M5S followers, including online content and comment posting. A restricted set of tools with enhanced participation features, such as voting, polling and decision making, are accessible only to subscribers. The M5S has gained a large number of subscribers in just a few years and currently boasts a membership roll of approximately 800,000 persons. Only about
100,000 of these are certified subscribers, while the rest continue to await the processing of their applications. Still, these figures exceed the registration numbers of Italy's other political parties, which have suffered membership declines in recent years. For instance, the most-voted-for party has experienced a membership decline from about 800,000 members in 2009 (Labate, 2013) to 240,000 in 2014 (Lo Sardo, 2014).

\section{Case analysis to understand the dynamic process of change}

In this section we proceed to the case analysis portion. We have different perspectives for analyzing each case. For the Panasonic case, we see how the community development process was formed within the project either offline or online. For the M5S case, the question was framed as what kind of online activities and interaction actually are done by people to increase the level of participation and engagement. Analysis was done based on the three key online activities proposed in the previous section, namely knowledge generation, information sharing of common interest, and creation of collective action. Through the analyses, we explore the link among all three elements and apply results to the smart city environment.

\subsection{Information sharing of common interest}

Regarding the first case, FSST aims at developing a sustainable (environmentally friendly) society which requires a long-term perspective. A new strategy is required for the creation of a sustainable community as well. Its processes must allow for and encourage the involvement of all stakeholders and local residents. It must provide a new value to foster both a sustainable community and a business model which is able to get a smart city project started. ICT plays an essential role in supporting any new service provisions within the new town.

Residents have even begun to organize yoga and hula dance clubs. People who are interested in learning hula can express their interest through the portal. The same applies for other topics. The town portal also acts as a social network service with a function similar to the "like" button for people to interact with one another, creating further communication among the residents. The town portal not only transmits information posted by residents but also works as a gateway to town services. For instance, residents can receive information about the city, the energy use levels in their homes, and 
monthly eco-life recommendation reports. They also can gain access to security cameras, reservations for car-sharing services, and electronic bicycles.

The main objective for the M5S online activities (Figure 4) is to include citizens (members and nonmembers) in all aspects of the political discourse. A key motivation for the imitation of the M5S is the lack of trust in the traditional political system, including lack of trust in the information provided by the political parties and the mass-media, which is considered fully dominated by the political elite. The online activities are hence initiated to provide an alternative way for people to have their say and an influence on society and decisions to be made.

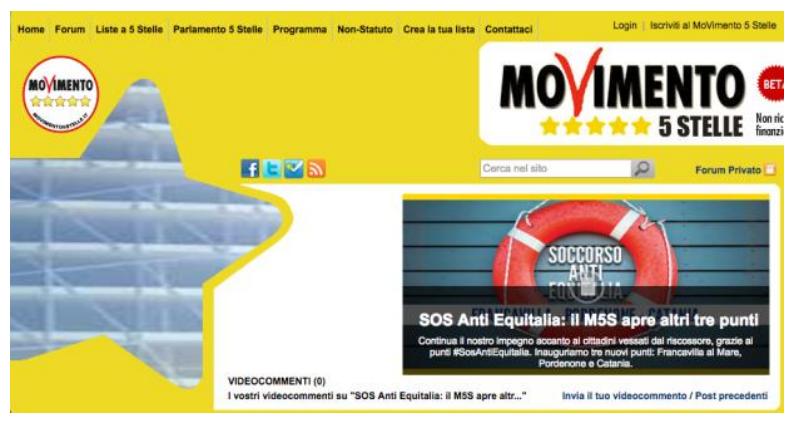

Figure 4. M5S web portal

To be able to take part in political decision-making processes, citizens are in need of access to information and the opportunity to share information. This involves both creating and circulating information [35]. Another objective is to facilitate the establishment of direct relationships for information circulation. Information sharing activities are found at both the local and the central level within the M5S. Locally, the Meetup-groups (consisting of a low number of members from the same geographical area) represent a key mechanism for information sharing activities. Through the Meetup-groups, everyone can disseminate information within the group as well as between groups and other entities within the movements. The Meetup-groups are free to make their own decisions on which tools to include, resulting in the use of various generic social media services (like Facebook, Twitter, and WhatsApp) as well as the use of other services more specifically designed for supporting activities within such small groups. At the central level, information sharing activities are more strictly designed and organized. Here, access to provided information is dependent on the role of each participant; representatives have access to most services, registered members to some, while followers (not being registered) are mainly left with the role of receiving information from others.

\subsection{Collective action}

The idea of collective action is doing something together [35]. In FSST, a sense of solidarity can be expected from this community during emergencies. Ever since the Great East Japan Earthquake of 2011, which was the largest earthquake ever recorded in Japan, "safety and security" has been a topic of concern. At FSST, two plans have been integrated into the city's development: the BCP (Business Continuity Plan) and the CCP (Community Continuity Plan). They take advantage of the communication networks in this community, creating a disaster assistance group for every 10-20 households, which in the case of an emergency will help provide smooth support to return residents to their normal lives.

In the wellness service field, FSST plans to develop an integrated community care system. This has not yet been implemented; however, it will enable the collection of all the health-related information of each resident for sharing with all related stakeholders (pharmacy, hospital, and local government). It is also supposed to contribute to enhancing collective action of residents with the aim of bettering health conditions.

Key activities within the M5S movement relate to collective action. Members are encouraged to actively participate in discussions and in the online decision-making processes. Collective actions include the need to be properly informed, to be actively involved in the discussions, and to participate in the decisions to be made in a timely manner. The M5S's online activities include mechanisms related to the "call for action," where members are informed and called upon when decisions are to be made. Technologies used to call for action include social networking platforms, microblogging platforms, and instant messaging tools. Recipients are free to ignore the calls to action. These mechanisms are most often connected to a structured decision-making process, linking collective action with online activities for knowledge generation.

\subsection{Knowledge generation}

Through the M5S's online activities, participants are not only allowed to distribute information but are also strongly encouraged to contribute to the production of information, hence, to knowledge generation activities. For instance, the M5S has 
introduced a system called Lex, where all members are invited to contribute to writing law proposals to be presented to the parliament. Through the system, the movement typically receives several thousand comments for each instance. While this number is impressive compared to the volume of input normally obtained from citizen participation within political decision-making processes, the huge volume presents a challenge for maintaining the level of quality of the knowledge generation activities. A large number of the comments state their agreement or disagreement with other comments made; others are less relevant to the topic being discussed. A key challenge for the $\mathrm{M} 5 \mathrm{~S}$ is to identify topical and good-quality contributions from the large volume of content created through online activities for knowledge generation.

We have no observation results to support knowledge generation in FSST, as the town has just opened and it is too early to draw conclusions; that will be a topic for future research to explore.

\section{Lessons learned and future research topics}

Prior studies within the smart city domain have mainly focused on the unchanging, hard elements of the city such as buildings, transportation and energy management, that are stable once installed. Our study contributed by focusing more specifically on the human side of the concept, discussing how online activities work for a smart city environment. While current focus areas within the smart city literature are clearly important, we here address the need for more research focusing on the participation of citizenry in decision-making processes as well as in the daily life and discussions that are key elements within all groups and societies. By bringing in knowledge from the e-participation area and the M5S case, we aimed to explore the effective design of online activities in a smart city project. The analysis results, that are still in an initial phase of the study, would provide new insights on how smart cities can be mobilized through community building and online human behavior (Figure 5).

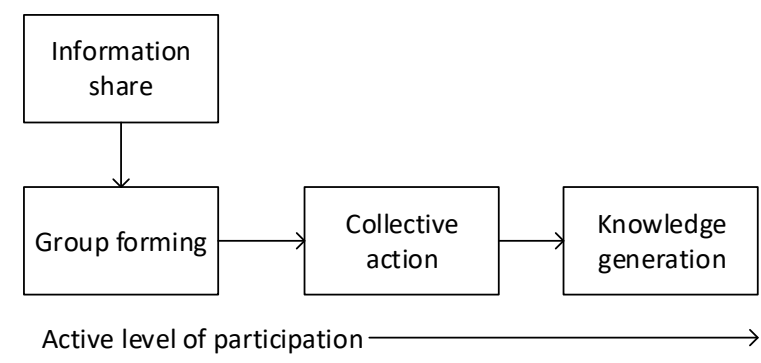

Figure 5. Online activity concept flow

Both smart city and e-participation cases show information sharing of common interest results in forming a local group. It is the first step and key to get citizen involved into the specific activities. Formed groups are a basis of further collective action and knowledge generation afterwards. Reforming and empowering neighborhood to visualize resource structure as well as their needs toward local administration is stressed in the previous study on smart cities [36]. Our finding is not new in this regard, however, it is beneficial to see this aspect from online activity perspective. Lessons learned that directly affect research and practice within the smart city domain, summarized as follows:

* There is a need to focus more on how to organize online activities within smart city initiatives. Lessons from the M5S case demonstrate the importance of considering how to organize online activities to fulfill the needs of the community. We argue that this also holds true within smart city initiatives. The thus-far very limited focus on how to organize the human and online activity portions of such initiatives may indicate that such activities are only implicitly considered important or are at least not being explicitly thought of as something to be designed and managed. Lessons from the M5S case pinpoint the importance of managing tensions, organizing for information sharing, designing for decisions to be made, and considering structural issues related to the organization of the ICT to be included.

* The three key components within online activities (knowledge generation, information sharing, and collective action) are all connected. Hence, the design and management of online activities need to consider how to support all three components in order to achieve the intended aims. Information sharing should be considered a key element that supports knowledge generation and collective action, whereas collective action is clearly needed for group forming with shared interested among residents. 
* Getting people involved in the decision-making process is the key to sustaining online activities. Sustained interest and involvement from citizens are really dependent on the feeling of being heard, involved, and included in the decisions to be made. The M5S has designed several mechanisms to keep people involved and satisfied as participants in decision-making processes, for instance, by calling for action when decisions are to be made. A large number of e-participation projects have failed quite quickly due to the fact that the citizens quickly realized that their involvement was neither important nor influential [37].

* Online activities need to be flexibly designed to allow a huge number of participants. A primary challenge with online activities, as illustrated by the M5S case, is the lack of quality control when a huge number of participants are involved. Systems that work nicely, providing a good overview when few participants are present, may end up lacking any quality control when a large number of participants are involved. For instance, the M5S got around 80,000 comments on one single issue to be decided upon, leaving no one to be able to focus on the bigger picture of what to include and why. Future initiatives should consider how to best maintain the flexibility needed as well as an acceptable level of quality when a large number of citizens are involved.

\section{Conclusion}

This paper contributes to smart city literature and practice in two respects: (1) it submits case discussions on how the soft elements of a smart city work, and (2) it explores the functioning of key elements of a smart city-providing a new perspective with a conceptualization of online activities. Our model for online activities within a smart city concept is still yet under the development, however, we see at least three implications to public policies. First, forming citizen groups is essential as a starting point of community building. Public administration plays a role to develop and maintain a digital platform which supports information sharing. Second, collective action emerged as a result of information share should be related to existing or newly created governmental/community services. Linkage between a real political/service process is a key to sustain citizen activities. Citizens/residents should be informed in a timely manner. Collective actions can be done both offline and online, however, ICT should be used as a gateway or means of connection to other functions within a smart city. Third, the size of community should be considered. As e-participation level is getting higher, a community tend to generate their own knowledge through collective action. Quality control of certain knowledge (writing law proposals in the M5S case) became challenge if an attempt succeeds collecting more individuals or groups than expected. So far, FSST haven't achieved this level, however, as their target population number is three-thousand, attention should be given to flexibility and quality control of each community.

We argued that online activities are a driving force with the power to enhance people's participation and possibility of applying insights to citizen engagement in a smart city initiative. Without designing and organizing these activities properly, a city obtains neither function nor dynamism as a living system. Eventually, a city stops growing and sustainability cannot be achieved. We are on the way to explore the organization of a smart city's dynamic structure. The question remains: how do these online activities enable the dynamic structure of a smart city? As future research topics, we should first investigate the detailed interconnections between three online activities of residents and find other activities, if applicable, in the FSST project and other smart city initiatives. In particular, the process of knowledge generation within a smart city environment should be investigated. As realizing sustainability requires human activities, which result in increasing quality of lives [38], knowledge generation and knowledge management might be a key for a smart city project to sustain. In addition, the M5S case implies the usefulness of social media; thus, the possibility for social media implementation in the FSST project should be explored as well.

\section{References}

[1] Alexander, C., A city is not a tree. Architectural Forum 122, 1965. 1: p. 58-61.

[2] Albino, V., U. Berardi, and R.M. Dangelico, Smart cities: Definitions, dimensions, performance, and initiatives. Journal of Urban Technology, 2015. 22(1): p. 3-21.

[3] Hollands, R.G., Will the real smart city please stand up? City, 2008. 12(3): p. 303-320.

[4] Höjer, M. and J. Wangel, Smart Sustainable Cities: Definition and Challenges, in ICT Innovations for Sustainability, L.M. Hilty and B. Aebischer, Editors. 2015, Springer International Publishing: Cham. p. 333-349.

[5] Caragliu, A., C. Del Bo, and P. Nijkamp, Smart Cities in Europe. Journal of Urban Technology, 2011. 18(2): p. 65-82. 
[6] Federici, T., A.M. Braccini, and Ø. Sæbø, 'Gentlemen, all aboard!' ICT and party politics: Reflections from a Mass-eParticipation experience. Government Information Quarterly, 2015. 32(3): p. 287-298.

[7] Nam, T. and T.A. Pardo, Conceptualizing smart city with dimensions of technology, people, and institutions, in Proceedings of the 12th Annual International Digital Government Research Conference: Digital Government Innovation in Challenging Times. 2011, ACM: College Park, Maryland, USA. p. 282-291.

[8] Pierce, P. and B. Andersson. Challenges with smart cities initiatives - A municipal decision makers' perspective. in Proceedings of the 50th Hawaii International Conference on System Sciences. 2017.

[9] Komninos, N., Intelligent cities: innovation, knowledge systems, and digital spaces. 2002: Taylor \& Francis.

[10] Chourabi, H., et al. Understanding smart cities: An integrative framework. in System Science (HICSS), 2012 45th Hawaii International Conference on. 2012. IEEE.

[11] Moss Kanter, R. and S.S. Litow, Informed and interconnected: A manifesto for smarter cities. 2009.

[12] Coe, A., G. Paquet, and J. Roy, E-governance and smart communities: a social learning challenge. Social science computer review, 2001. 19(1): p. 80-93.

[13] Yovanof, G.S. and G.N. Hazapis, An Architectural Framework and Enabling Wireless Technologies for Digital Cities \& Intelligent Urban Environments. Wireless Personal Communications, 2009. 49(3): p. 445-463.

[14] Mitchell, W.J., Placing Words: Symbols, Space, and the City. 2005, MA, USA: The MIT Press.

[15] Rahman, M.M. and S.A. Rajon. An effective framework for implementing electronic governance in developing countries: Bangladesh perspective. in Computer and Information Technology (ICCIT), 2011 14th International Conference on. 2011. IEEE.

[16] Veit, D. and J. Huntgeburth, Foundations of digital government. Leading and Managing in the Digital Era, 2014. 158.

[17] Medaglia, R., eParticipation research: Moving characterization forward (2006-2011). Government Information Quarterly, 2012. 29(3): p. 346-360.

[18] Sæbø, Ø., J. Rose, and L.S. Flak, The shape of eParticipation: Characterizing an emerging research area. Government Information Quarterly, 2008. 25(3): p. 400428.

[19] Faraj, S., S.L. Jarvenpaa, and A. Majchrzak, Knowledge collaboration in online communities. Organization science, 2011. 22(5): p. 1224-1239.

[20] Majchrzak, A. and M.L. Markus, Technology affordances and constraints in management information systems (MIS). 2012.

[21] Majchrzak, A., et al., The contradictory influence of social media affordances on online communal knowledge sharing. Journal of Computer - Mediated Communication, 2013. 19(1): p. 38-55.

[22] Preece, J., Online communities: Designing usability and supporting socialbilty. 2000: John Wiley \& Sons, Inc.

[23] Fulk, J. and G. DeSanctis, Electronic communication and changing organizational forms. Organization science, 1995. 6(4): p. 337-349.
[24] Shirky, C., Here comes everybody: The power of organizing without organizations. 2008: Penguin.

[25] Butler, B., et al., Community effort in online groups: Who does the work and why. Leadership at a distance: Research in technologically supported work, 2002: p. 171194.

[26] Zammuto, R.F., et al., Information technology and the changing fabric of organization. Organization Science, 2007. 18(5): p. 749-762.

[27] Jung, Y. and K. Lyytinen, Towards an ecological account of media choice: a case study on pluralistic reasoning while choosing email. Information Systems Journal, 2014. 24(3): p. 271-293.

[28] Faraj, S., et al., Online Community as space for knowledge flows. 2016.

[29] O'Mahony, S. and F. Ferraro, The emergence of governance in an open source community. Academy of Management Journal, 2007. 50(5): p. 1079-1106.

[30] Olson, M., The logic of collective action. Vol. 124. 2009: Harvard University Press.

[31] Flanagin, A.J., C. Stohl, and B. Bimber, Modeling the Structure of Collective Action 1 This material is based upon work supported by the National Science Foundation under Grant No. 0352517. The authors are equal contributors to this article. Communication Monographs, 2006. 73(1): p. 29-54.

[32] Wasko, M.M. and S. Faraj, Why should I share? Examining social capital and knowledge contribution in electronic networks of practice. MIS quarterly, 2005: p. 3557.

[33] Ostrom, E., Collective action and the evolution of social norms. Journal of Natural Resources Policy Research, 2014. 6(4): p. 235-252.

[34] New Energy and Industrial Technology Development Organization, Smart city program in Amsterdam (written in Japanese), in NEDO foreign cases report. 2009: Tokyo, Japan.

[35] Braccini, A.M., T. Federici, and Ø. Sæb $\varnothing$, Exploring Collective Action Dynamics in Online Communities from a Critical Realist Perspective, in Blurring the Boundaries Through Digital Innovation. 2016, Springer. p. 271-282.

[36] Á. Oliveira and M. Campolargo, From Smart Cities to Human Smart Cities, 2015 48th Hawaii International Conference on. 2015. IEEE.

[37] Sæbø, Ø., L.S. Flak, and M.K. Sein, Understanding the dynamics in e-Participation initiatives: Looking through the genre and stakeholder lenses. Government Information Quarterly, 2011. 28(3): p. 416-425.

[38] Höjer, M. and J. Wangel, Smart sustainable cities: definition and challenges. ICT Innovations for Sustainability, 2015, Springer: 333-349. 